\title{
¿Es posible capacitar a los residentes de anestesiología en trasplante hepático en Argentina?
}

\author{
Aponte Gatica JF. ${ }^{1}$, Sommer Alias D’abate M. ${ }^{1}$, Cicconi E. ${ }^{1}$, Waldhorn M. ${ }^{1}$, Domínguez MX. ${ }^{1}$, Teijido C. ${ }^{1}$ \\ 1 Hospital Italiano, Buenos Aires, Argentina.
}

Introducción: En los últimos 30 años el trasplante de órganos se ha consolidado como tratamiento médico. En 2018 se realizaron 432 trasplantes hepáticos, justificando la necesidad de creación de múltiples equipos, capaces de responder en simultáneo a esta demanda. Dentro de estos equipos se precisan anestesiólogos con experiencia, conocimiento y habilidades técnicas que permitan llevar un procedimiento de este nivel de complejidad. La habilitación en trasplante requiere en Argentina para su acreditación justificar experiencia. Sin embargo, no todo los programas de residencia están asociados a un centro de trasplante. Esto requiere una revisión de las inequidades en cuanto a oportunidades de entrenamiento en trasplante en las diversas instituciones. La pregunta que surge entonces es ¿dónde se están formando los anestesiólogos de estos futuros equipos? y ¿adquieren capacitación suficiente durante los años de residencia?

Métodos: Se realizó una búsqueda en la central de reportes de procedimientos del Sistema Nacional de Información de procuración y Trasplante en la República Argentina (SINTRA) de los trasplantes hepáticos realizados durante el período comprendido entre 01/01/2014 al 31/12/2018. Se los agrupó por institución de trasplante (privado o público) y provincia. En base a la cantidad de trasplante se dividieron las instituciones en alto (más de 60 trasplantes en 5 años) y bajo volumen (menos de 60 trasplantes en 5 años). El segundo análisis que se realizó es el de determinar cuáles de los centros tienen formación de residencia en anestesiología.

Resultados: Durante el período estudiado se realizaron 1.845 trasplantes hepáticos en 25 instituciones (8 públicas y 17 privadas) del país, con distribución en 6 provincias (CABA, Buenos Aires, Córdoba, Mendoza, Santa Fe, y Formosa) (Figura 1). Solo 10 instituciones ( 3 públicas y 7 privadas) realizaron más de 60 trasplantes por lustro (total 1.587 trasplantes, $86 \%$ del total), teniendo 7 de ellas un programa de formación de residencia en anestesiología (Figura 2).

Conclusiones: Diez instituciones ( 3 públicas y 7 privadas) realizaron más de 60 trasplantes por lustro, y en conjunto realizaron 1.587 trasplantes ( $86 \%$ del total). De estas 10 instituciones 7 tienen un programa de formación de residencia en anestesiología, y podrían acreditar que los residentes hayan participado en su formación en la asistencia de 20 pacientes trasplantados hepáticos, cumpliendo con el requerimiento del INCUCAI y organismos internacionales. Sería interesante que los hospitales con residencias, tengan presente que sus residentes roten por estas unidades con Trasplante para que adquieran la experiencia necesaria.

https://doi.org/10.25237/congresoclasa2019.66 